УДК 81.23

DOI: 10.33184/YVDK-2021-04-30.56

Н.П. Пешкова (проф. БашГУ, г. Уфа)

\title{
О НОВЫХ ТЕНДЕНЦИЯХ В ТИПОЛОГИЧЕСКИХ ИССЛЕДОВАНИЯХ ТЕКСТА
}

В статье рассматриваются новые тенденим типологиеских исследованийтекста, возникаюиие в результате изменения условий современной коммуникапии, появления новьх типов текста и особьгх техник организапи его содертжания и формы. К последним моэнно отнести гипертекст, гибридный и креолиованный тексты. Как показывает анали, разработанный автором принаип типологчческих исследованай, основанньй на законе корреляипи характеристик внутренней и внешней структур текста, сохраняет свою актуальность и в современных условия. Данньй принип продолжает действовать в прочессах порондения и понимания новых типов текста, функционируюицих вусловиях компьютерно-опосредованнойкоммуникапиц.

Ключевье слова: тип текста, пипологческая модель, поровндение/понимание текста, автор, адресат, сетевая языковая личность, компьютерно-опосредованная коммугикаиия.

The article considers some new trends in the text-typology researches regarded as a result of: changes taking place under the conditions of modern communication; forming new text-types; and applying new techniques of structuring text content and form. The latter include hyper-text, hybrid and creolized texts. According to the analysis presented in this paper the principle of the text-typology research developed earlier by the author and based on the law of correlation between the characteristics of the internal and external text structure still stays relevant. This principle "works" in the processes of new 
text-types production and comprehension under the conditions of computer-mediated communication.

Key words: text-type, typological model, text production/comprehension, author, addressee, network linguistic personality, computer-mediated communication.

Типологическая концепция исследования текста, разработанная нами на рубеже веков (1980-ые-2000-ые гг.), опиралась на общие закономерности, лежащие в основе взаимоотношений между внутренней структурой и внешней формой текста, отражающие глубинные связи между физическим и психическим, или материальным, данным нам чувственном восприятии, и идеальным, скрытым за внешней оболочкой; закономерности, проявляющиеся в условиях реальной коммуникации, т.е. порождения и понимания коммуникантами различных типов письменных речевых произведений [Пешкова 2015].

Изменения, происходящие в коммуникативных процессах последнего десятилетия, привели к возникновению новых особенностей коммуникации и ее новых видов, а также и к появлению новых типов текстов. Новые условия коммуникации и, прежде всего, ее компьютерно-опосредованная форма, способствовали возникновению таких тенденций в процессах продуцирования текста, как гибридизация; конденсирование информации, сопровождаемое уменьшением «материального» объема текста; уплотнение интертекстуальных связей, ведущее к изменениям соотношения эксплицитной и имплицитной информации, в пользу увеличения последней; появление новых техник организации содержания, таких как гипертекст, гибридный текст, креолизованный текст [Гришаева 2021: 37].

Исчезают такие типы текста, как написанные от руки личное/деловое письмо и поздравительная открытка, дневник и телеграмма; появились новые виды письменной коммуникации e-mail, sms, рабочий чат. Исследователями текста отмечаются изменения в статусе «смеховой культуры» и возрастающее использование в речевой коммуникации таких стратегий, как карнавализация, стеб, троллинг, пранк и т.п. [op.cit.: 38]. 
Мы могли бы добавить к этому, что типы письменного текста, сохранившие свою значимость в современной жизни, как, например, научная статья, монография, учебный текст, известные нейтральным стилем изложения фактов, также претерпевают изменения под воздействием тенденции к свободному проявлению эмоций в текстах любого типа, превращаясь в эмоциогенные речевые произведения по форме представления информации.

Несмотря на все изменения, происходящие в процессах продуцирования и варьирования текстов, а также и в процессах восприятия и понимания, некоторые существенные моменты наших типологических разработок сохранили свою актуальность в свете современной междисциплинарной парадигмы текстовых исследований.

Опираясь на теоретическое наследие лингвистики текста 20-го века и психолингвистические труды 20-го-начала 21 вв. и используя обозначенный выше принцип типологического исследования, мы разработали несколько моделей корреляции текстовых характеристик, проверенных с применением специальной компьютерной программы (программа создавалась в отделе прикладного языкознания Института языкознания РАН). Выявленное нами регулярное действие механизмов корреляции на обширном экспериментальном материале научных, учебных, научно-популярных и медийных текстов на трех языках, русском, английском и французском, позволило утверждать, что действующие закономерности могут претендовать на статус закона корреляции между характеристиками, принадлежащими как одному уровню, так и разным уровням текста [Пешкова 2015].

Разработанные модели были исследованы экспериментально в процессах порождения и понимания письменного текста, иными словами, в процессе его «жизненного цикла», от формирования замысла автором до постижения смысла адресатом. «Жизненный цикл» текста мы представляли в виде схемЫ: ПОРОЖДЕНИЕ↔ТЕКСТ↔ПОНИМАНИЕ или ЗАМЫСЕЛ↔ТЕКСТ $\leftrightarrow$ СМЫСЛ [op.cit]. 
Полученные экспериментальные данные подтвердили нашу гипотезу о том, что продуцирование письменного текста представляет собой алгоритм (безусловно, обладающий гибкостью, присущей языковым алгоритм), реализация которого предполагает, что ряд заданных автором характеристик текста, входящих в «ядро» инвариантных характеристик модели, обусловливает появление вариативных, «ядерных» и периферийных, характеристик речевого произведения.

На уровне понимания результаты эксперимента свидетельствовали о значимости характеристик внутренней структуры, таких как еe тип, имеющий графическое представление в форме денотатного графа, пресуппозиция, внутренняя связность и внутренняя развернутость, определяющих во многом способы и стратегии понимания.

Нужно отметить, что, как и в любой области науки о языке, лингвистические исследования текста, включая его типологию, осуществлялись преимущественно с позиции автора речевого произведения. Нас же в экспериментальных исследованиях в не меньшей, а возможно, и в большей степени интересовала позиция адресата. В связи с этим необходимо сказать несколько слов об особенностях, присущих современному адресату текстовой информации.

Многие исследователи отмечают, что развитие информационных технологий сопровождалось изменениями в социокультурной и языковой среде и формированием нового коммуникативного пространства, что неизбежно вело и возникновению нового типа коммуникантов. Первым, как известно, появился термин «виртуальная языковая личность», под которым обычно понимался особый тип личности, «обусловленный ситуацией виртуального общения, влияющей на изменение уровней структуры языковой личности, в особенности мотивационного уровня» [Лутовинова 2013:3].

В настоящее время используется также термин «сетевая языковая личность». Так В.И. Карасик отмечает, что одной из характеристик сетевой языковой личности в социальном аспекте является ее существование «в новом соотношении приватного и публичного поведения», исследование нового типа языковой 
личности «необходимо для понимания тенденций развития коммуникации и осмысления новой ценностной картины мира, отраженной в языковом сознании и коммуникативном поведении» [Карасик 2021:58]. Нельзя не заметить, что большую часть нашей экспериментальной аудитории представляют испытуемые данного типа, участвующие в интернеткоммуникации в качестве адресатов и авторов интернет-текстов, одновременно.

В упоминаемом выше исследовании В.И. Карасика выделяются восемь жанров сетевого дискурса. Среди них особый интерес для нас представляют, так называемые, «репортативы», «социативы» и «креативы» [op.cit.: 59], реализуемые в форме различных типов текста. Первые - в виде сообщений об актуальных новостях, вызывающих интерес у целевой аудитории. Вторые обычно отражают общие интересы определенной группы интернет-коммуникантов в той или иной предметной области и функционируют в виде как сообщений, так и рассуждений на общую для пользователей тему. Третьи являются художественным творчеством, представленным вербальными, невербальными и креализованными текстами, например, в виде картин, сопровождаемых комментариями, мультимедийными проектами и т.п.

В процессе интернет-коммуникации и новостные сообщения в микроблогах («репортативы»), и тексты в жанре «социатива», и «креативы» всегда сопровождаются комментариями, которые мы характеризуем как «встречные тексты» [Новиков 2003], поскольку по своей природе тексткомментарий соответствует различным видам реакций, составляющих «встречный текст» - от оценки, ассоциации и визуализации до мнения, аргументации и прогноза. Таким образом, интернет-адресат становится автором новых «встречных» текстов, а автор текста-стимула принимает на себя роль адресата.

Можно отметить еще одну особенность «сетевого» общения - усиление роли «кода» как проводника информации, понятной только участникам коммуникации внутри определенной группы, или маркера для дифференциации 
коммуникантов на «своих» и «чужих». Идея общего кода как посредника общения, с помощью которого адресат «дешифрует значение интересующего его сообщения» [Лотман 1998: 25], безусловно, не нова. Однако, используемый в текстах жанра «социатива» подобный код не просто «не всегда успешно декодируется «чужими» коммуникантами» [Куковская 2021: 74], он может приобретать значение запрета на информацию для «чужих».

В качестве примеров подобных кодов можно привести аббревиатуры и целые слова на английском и русском языках, используемые как профессиональными монтажерами, так и потребителями их продукции, т.е. различных трейлеров: $V F X$ visual effects, визуальныле эффекты; SFX - sound effects, звуковые эффекты; Mographs - motion graphics, анимированнье объекты; секвенция - набор сиен; 3 - закадровая реплика.

Нужно сказать, что наличие такого кода представляется одним из типообразующих признаков современного интернеттекста, связанного, не обязательно, с общением в профессиональном чате, но и в группе, объединенной интересом к тому или иному объекту массовой культуры.

Экспериментальное изучение текстовых характеристик, составивших нашу типологическую систему, с позиции адресата, на этапе восприятия и понимания информации в форме различных видов текста подтверждает их значимость и для новых вариантов известных типов, и для вновь появившихся типов текста. Все изменения происходящие на уровне содержания текста - его уплотнение, увеличение имплицитной информации. последствия гибридизации и креолизации - отражает денотатный граф как инструмент экспликации внутренней содержательносмысловой структуры. Доминирование в ней элементов «дерева» или «сети» позволяет прогнозировать, будет ли данный тип структуры содержания текста способствовать его эффективному пониманию, облегчать его или, напротив, усложнять процессы восприятия и интерпретации текста адресатом. Не теряет своей значимости и такая характеристика внутренней структуры, как пресуппозиция, представляющая собой основу для осуществления механизмов понимания и осмысления сообщения 
в целом. Внутренняя связность и степень внутренней развернутости также «работают» на обеспечение условий успешного понимания для адресата.

Изменения внутренней структуры влекут за собой преобразования во внешней форме. Они могут менять способ изложения, «сжимая» его посредством отсылок к другим текста, организуя содержание и форму на основе принципа гипертекста. Можно с уверенностью сказать, что сохраняют свою актуальность такие характеристики, как модальность, используемая автором в качестве инструмента настройки адресата на запланированное им отношение к информации, однако, считываемая реципиентом по-разному, индивидуально и субъективно. Свидетельством этому являются реакции субъективной оценки, зачастую эмоционального характера, преобладающие во «встречных текстах» адресатов-участников экспериментальных исследований.

Таким образом, можно утверждать, что разработанный нами принцип типологического изучения текстов продолжает работать на новых типах речевых произведений, выявляя как особенности их внутренней структуры и внешней формы, так и закономерности их взаимосвязи и взаимозависимости.

\section{ЛИТЕРАТУРА}

1. Гришаева Л.И. Пределы варырования текста в коммуникации: закономерность и/или случайность? // Лингвокультурные аспекты глобализационных процессов: социокультурный контекст и динамика речевых практик: тезисы докладов II Международной конференции, Москва, 25-26февраля 2021г. М.:МГЛУ, 2021.-С. 36-39.

2. Карасик В.И. Сетевая языковая личность // Лингвокультурные аспекты глобализационных процессов: социокультурный контекст и динамика речевых практик: тезисы докладов II Международной конференции, Москва, 25-26февраля 2021г. М.: ФГБОУ ВОМГЛУ, 2021.-С. $58-59$.

3. Куковская А.В. Группообразующий семиотический код англоязычного интернет-дискурса блогеров в контексте социокультурных практик // Лингвокультурные аспекты глобализационных процессов: социокультурный контекст и динамика речевых практик. тезисы докладов II 
Международной конференции, Москва, 25-26 февраля 2021г. М.: МГЛУ, 2021.- C. 73-74.

4. Лотман Ю.М. Структура художественного текста // Лотман Ю.М. Об искусстве.-СПб.: «Искусство-СПБ», 1998.-С. 14-285.

5. Луговинова О.В. Языковая личность в виртуальном дискурсе. Автореф. дисс. ... д-рафилол. наук. Воронеж, 2013. -42 с.

6. Новиков А.И. Текст и «контртекст»: две стороны процесса понимания // Вопросы психолингвистики, 2003, № 1.-С. 6476.

7. Пешкова Н.П. Типология научного текста: психолингвистическийаспект (на материале научных, научно-популярных, технических текстов): монография, 2-еизд., доп. иперераб. - Уфа: РИЦБашГУ, 2015. -292 с.

СПешкова Н.П., 2021 г. 